Chapter Eight

History and techniques of the kimono

Makoto Mori

Edited by Pip Dickens

\title{
History of the kimono
}

The original meaning of the word 'kimono' is 'clothing', although today it is often translated as 'something to wear'. In modern-day Japan the term also often refers to traditional Japanese clothing in general. Although the history of Japanese clothing prior to the Nara period (710-94) is not known in great detail, during the Heian period (794-1185) there are records that describe the clothing of the day. Here we find evidence of the origin of the contemporary kimono in the kosode, which was originally worn by the aristocracy as an undergarment.

The kosode is a garment with a body, sleeves and a pair of collars that drape from both shoulders and cross over each other in front of the chest. Kosode means 'small cuffs'; another type of clothing worn prior to the kosode had a larger cuff opening - as wide as the length of the sleeves - and was called osode (see Figures 8.1, 8.2). Clothes for the nobility during the Heian period had smaller cuffed openings in order to keep the body warm, so the kosode became a popular undergarment for the nobility from the end of the tenth century through to the beginning of the eleventh century. ${ }^{2}$ The kosode became popular with aristocrats as an outer garment from the latter period of the Heian period to the beginning of the Kamakura period (11851333), and many nobles wore a kosode tailored from gorgeous cloth.

A samurai's daily clothing (or formal public clothing) since the Heian period was a tubeshaped single costume called teboso, which was very similar in shape to the nobility's kosode undergarment. ${ }^{3}$ In the Kamakura
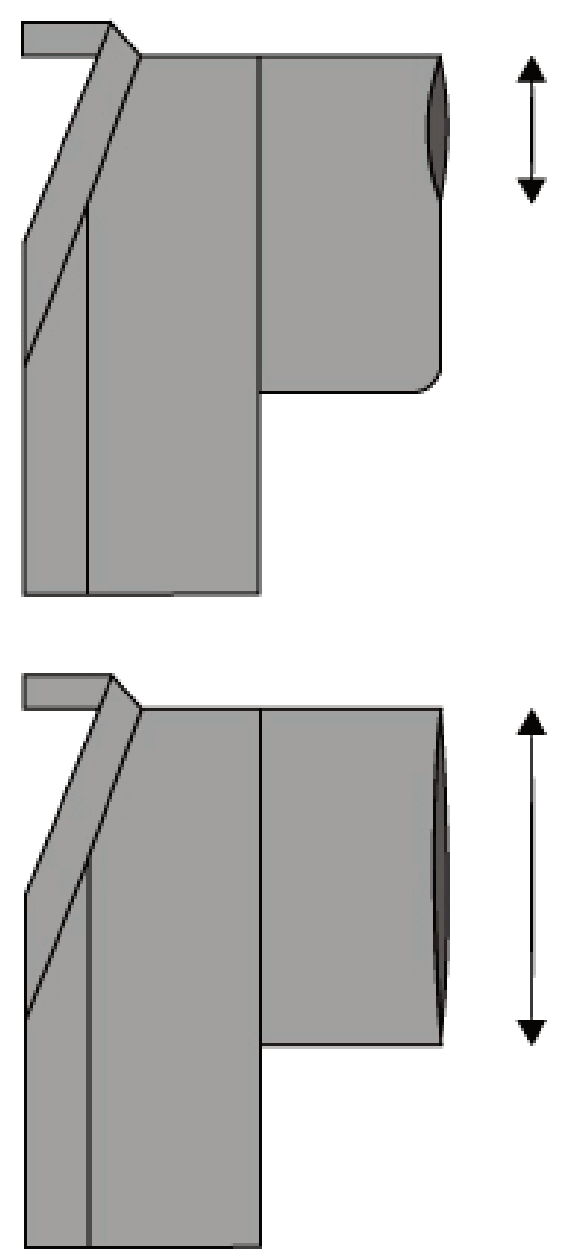

Figure 8.1 The kosode (top) and osode (bottom) were classified by the size of the cuff.

period (1185-1333) samurai began to call the teboso garment kosode. Later, kimonos worn by the general public also began to be referred 


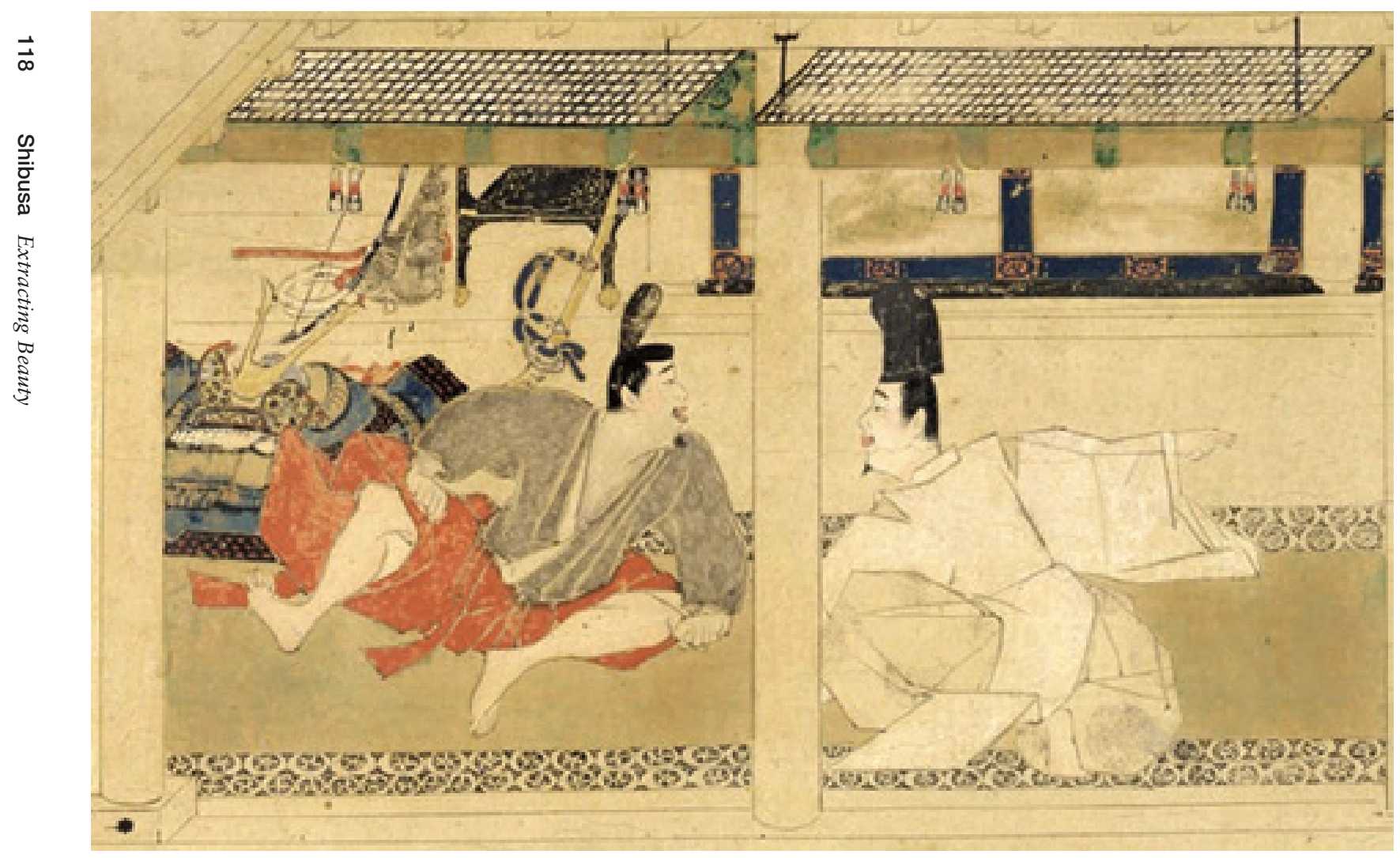

Figure 8.2 The figure on the left wears a kosode; the figure on the right wears an osode. The kosode is worn under the osode. Detail from The Illustrated Tale of the Heiji Civil War, 'The Imperial Visit to Rokuhara', Kamakura period (thirteenth century), (c) Tokyo National Museum

to as kosode because of the similarity of their shape. Ordinary people's teboso had a white ground without a pattern and were worn as outer garments. Occasionally, plain or easy tiedyeing was applied, but there were often bans on decoration of any kind.

From the late Muromachi period (1336$1573)$ to the Momoyama period (1568-1603) the kosode developed further, with direct similarities to today's kimonos. During this time Japan was often engaged in intensive warfare (both feudal and with the Mongols), which led to a general shortage of textiles and clothing. As a result, the simple kosode was adopted as the formal outerwear among samurai in the ascending class. Its smaller sleeves were also more practicable for physical movement. Thus the kosode became common throughout society, and not merely the exclusive garment of the nobility.

During the Heian period (794-1185), the narrow tube-shaped sleeves of the kosode became larger, although the cuff width remained almost the same. By the Momoyama period (1568-1603) the kosode shape had evolved into a configuration similar to the modern kimono. We also know that the word 'kimono' had become synonymous with kosode; for example, it is used in a report by the Portuguese missionary Joao Rodrigues, who came to Japan in around $1577 .{ }^{4}$ We can assume, therefore, that people began to use the word 'kimono' to mean not only clothing in general, but to refer specifically to the kosode.

As economic prosperity increased during the Muromachi and Momoyama eras, and through to the Edo period (1603-1868), female apparel became more decorative, thanks to the relatively peaceful and prosperous social conditions. Patterns on clothes became larger, and loose clothes with longer sleeves, or length, became popular (see Figure 8.3). Despite the Edo shogunate often prohibiting the wearing of this kind of 
clothing, the advent of bolder patterns and highly innovative yuzen techniques (handapplied decoration of textiles, described below) heralded an explosion in kimono design. The Edo period represents the pinnacle of traditional kimono design (see Figures 8.4 and 8.5), and many modern designs are influenced by kimonos from this period.

From the Meiji period (1868-1912), Japanese leaders encouraged people to adopt Western style dress in order to demonstrate Japan's alignment with the modernising movement that was taking place in Europe and the USA. During this period, Japan's leaders were either nobility or daimyo (feudal lords) and still tended to wear the osode. However, the 'modernisation' policy impacted dramatically on Japanese dress and gradually the meaning of terms such as osode and kosode evaporated. It was from this period onwards that the most commonly used term to describe such clothing was generally acknowledged as 'kimono' (see Figure 8.6).

At the beginning of the Showa period (1926-89), both Western-style dress and traditional Japanese clothes were worn by the general public. The popularity of Western-style

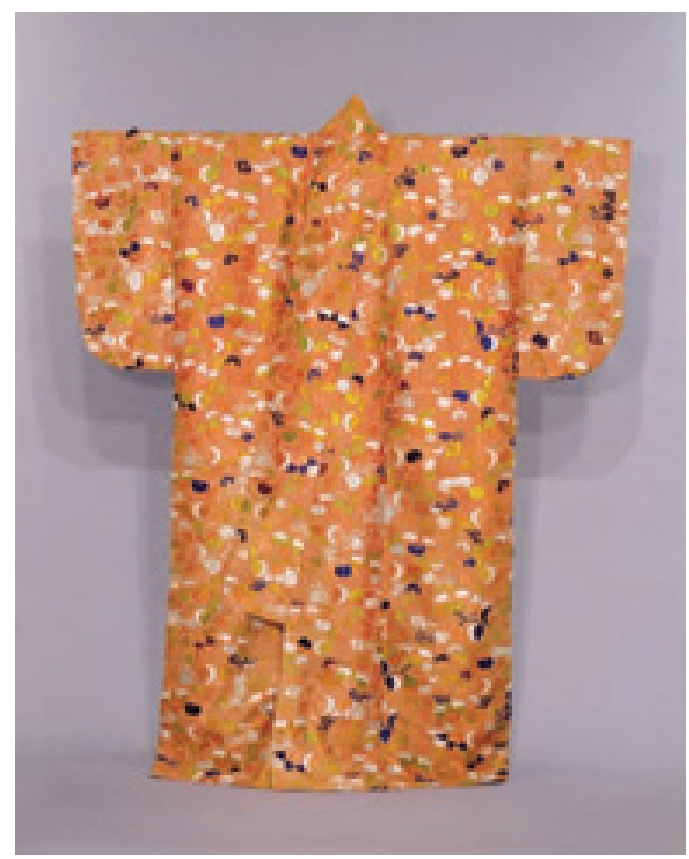

Figure 8.3 Kosode from the sixteenth century, showing characteristic elements of the Momoyama period, both in the skilful manipulation of small-pattern repeats, and the wide body and narrow sleeve construction. Portraits and other paintings of the day provide evidence that kosode such as this were worn on formal occasions as the outermost robes of high-ranking warrior-class women.@ Kyoto National Museum

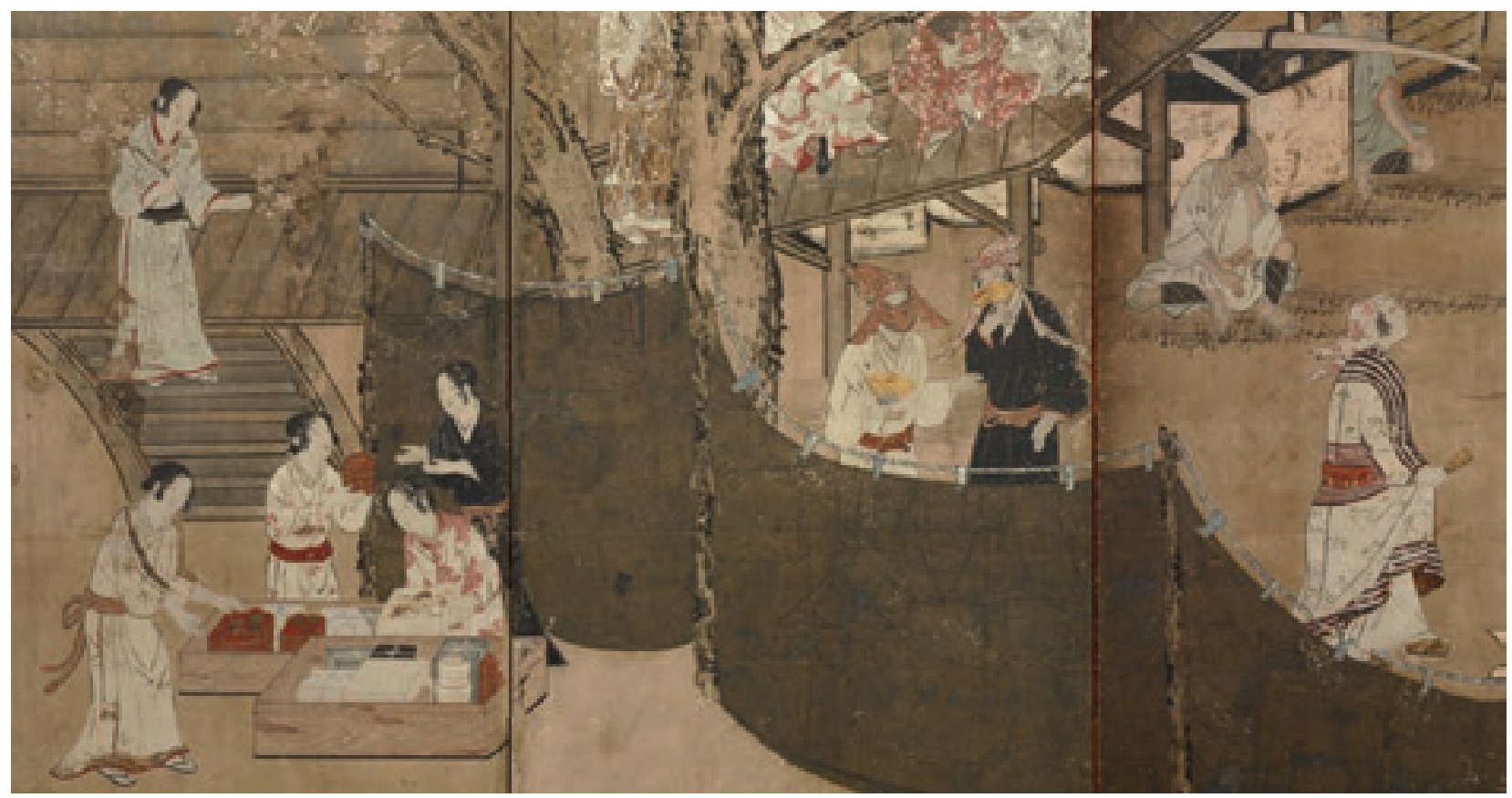

Figure 8.4 Clothes worn at the beginning of the Edo period are evident in this picture. The kosode shape has evolved to what is very similar to the modern kimono. However, the obi is thinner and the sleeves are smaller. Detail from Kano Naganobu, Merrymaking Under the Cherry Blossoms, Azuchi-Momoyama-Edo period (seventeenth century), ( ) Tokyo National Museum 


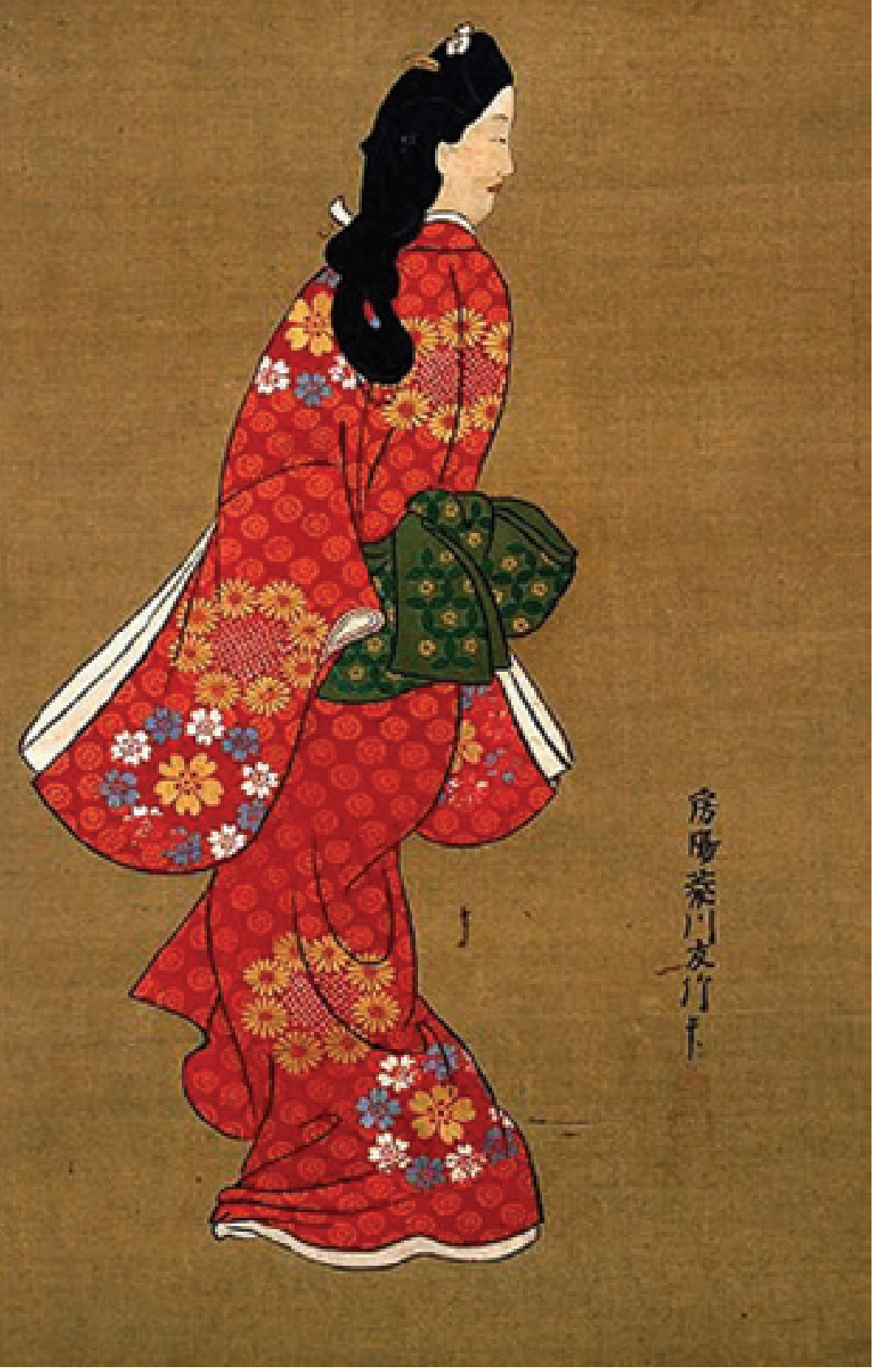

Figure 8.5 In the peaceful and economically stable social conditions of the Edo period, female apparel became more decorative. The furi-sode (longsleeved kimono) is an example. It is thought that the purpose of its long, fully open sleeves was originally to regulate the temperature of children, but the flowing design also became popular with women for decorative rather than practical reasons.

As a result, these long-sleeved characteristics have become associated with the expression of love by the female wearer. Hishikawa Moronobu, Beauty Looking Back, Edo period (seventeenth century), (C) Tokyo National Museum 

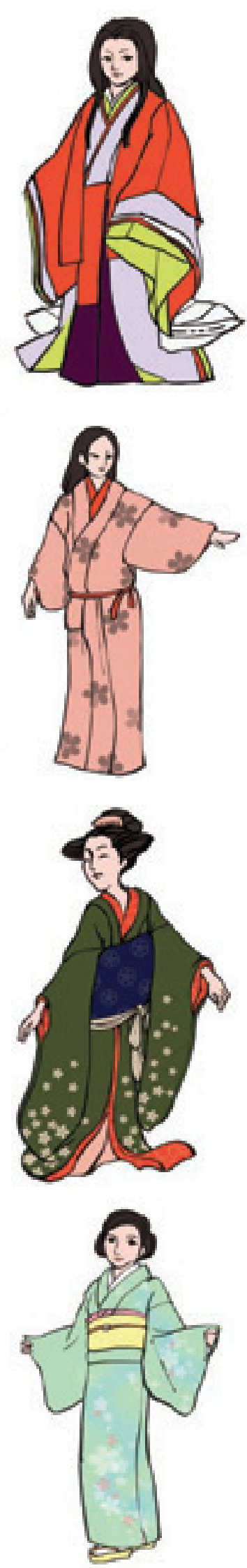

Heian period: The kosode is worn under noblemen's clothes.

Early Edo period: The kosode is adopted as the daily formal outerwear in the ascending classes. The sleeve is round and the obi (sash) is thin. Garments of this period feature a bold pattern design.

Late mid-Edo period: Female garments become more decorative. The patterns become larger and the garment is generally more loose fitting. The sleeves are also longer.

Meiji period to Showa period: The design of the kimono becomes more spectacular, with a wider range and combination of colour made possible by the introduction of chemical dyes.

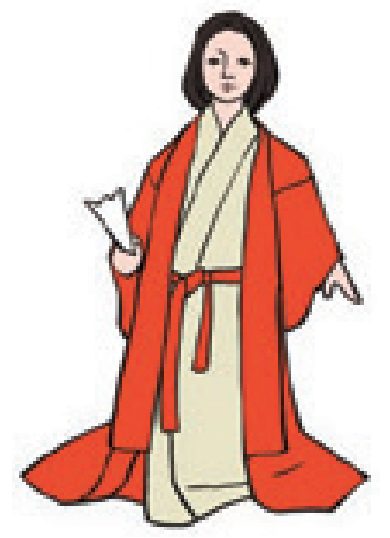

$\vec{N}$

Late Muromachi period to Momoyama period: The kosode is adapted as the daily outerwear in the ascending class. It is designed to have smaller sleeves and to suit physical activity.

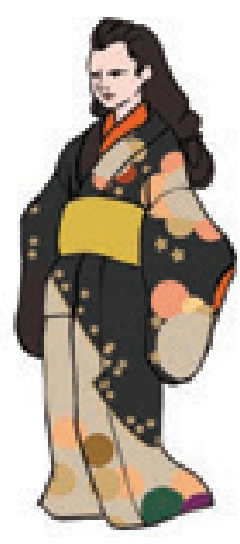

Early mid-Edo period: The garment becomes more luxurious. The obi is wider and the sleeves are longer. The

pattern is less bold, so that the wide obi breaks up the overall design. The sleeves become squarer in shape.

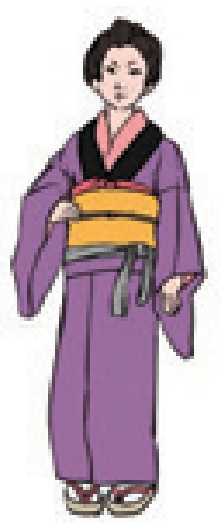

Late Edo period: The design of the kosode is much more understated and simple, whereas the undergarments are lavishly decorated.

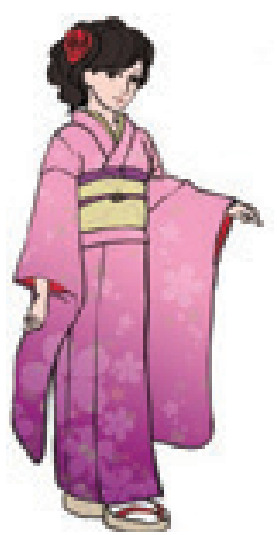

Contemporary:

The kimono is now mostly worn at traditional events and as formal wear.

Figure 8.6 The transition from kosode to kimono. Illustrations (C) Misa Sato 
dress increased in line with Japan's economic growth, and became the formal preference in the workplace. Fewer women were able to put on the kimono unassisted, and its appearance became rare by the mid-1950s. However, the kimono was still popular attire at traditional events, celebrations and as general leisure wear.

\section{History of Kyo-yuzen}

Some of the most popular kimonos are those utilising Kyo-yuzen technique - a method of dyeing kimono, which developed in the Edo period (1603-1868). Kyo-yuzen means specifically yuzen-zome dyed in the city of Kyoto - a yuzen pattern for a kimono dyed in Kyoto. The production methods can be roughly classified into four types: tegaki yuzen, katazome, machine printing and inkjet textile printing. This section describes the development of the production methods of Kyo-yuzen.

Yuzen is named after the fan artist Miyazaki Yuzensai, who lived in Kyoto in the mid-Edo period. His designs became popular (see Figure 8.7) and were utilised for kosode as well as fans. His designs formed the basis of kimono designs that are still echoed in contemporary design. ${ }^{5}$ The development of this technique was a consequence of a ban imposed in 1683 by the Edo shogunate on wearing (and making) luxurious costumes that used thin silk, crepe or embroidery. As a result, people sought methods of producing colourful kimonos that avoided traditional embellishments such as embroidery, pasting foil or tie-dyeing. These traditional decorations could stress and damage the texture of fine silks and other fabrics. In contrast, yuzen-zome was an innovative technology of dyeing patterns on to cloth as if painting a picture.

The splendid colours of yuzen were widely enjoyed by middle-class people - who were steadily gaining wealth and status - as well as the aristocracy and samurai. Its wide popularity paved the way for phenomenal advances in technology and application. One of the innovative aspects of the technique is that it prevented colour bleeding, which was particularly important when using many colours or creating complicated patterns with many colours. While there was already a traditional practice of using glue as a resistdyeing technique, yuzen-zome improved upon this and was seminal in the expansion of elaborate kimono design. ${ }^{6}$

No predetermined pattern was used when the process of yuzen-zome first began. Instead, the outline of a drawing on the fabric was made, using a piping implement and a starch called itome nori. ${ }^{7}$ Colours were painted inside the itome nori outline with a brush, and were then fixed. The next step was to put a thick layer of starch called fuse nori on the coloured design to protect it from bleeding. Then the background colours were applied. After washing and drying to remove the starch, the itome nori outline was revealed as perfect white lines of regular width that separated individual elements of the drawing for example, individual flower petals. The process amplified gestural and physical expression in the designs through the strength of the movement of the brush, coloured layers and colour gradation. Yuzen-zome is an important and flexible technology that has been passed down from generation to generation. It is now more commonly known as tegaki yuzen (meaning 'hand painted', see Figure 8.8).

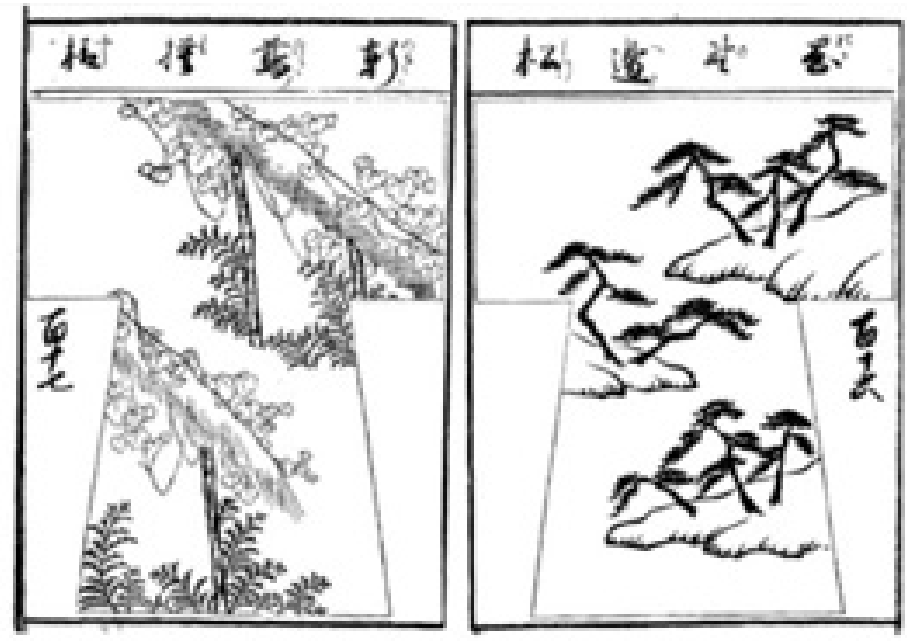

Figure 8.7 Miyazaki Yuzensai's 1692 book of designs promoted the kimono across Japan, and was a major influence on the spread in popularity of yuzen-printed kimonos. Miyazaki Yuzensai, Yosei Hinakata, 1692, Wayo Women's University 

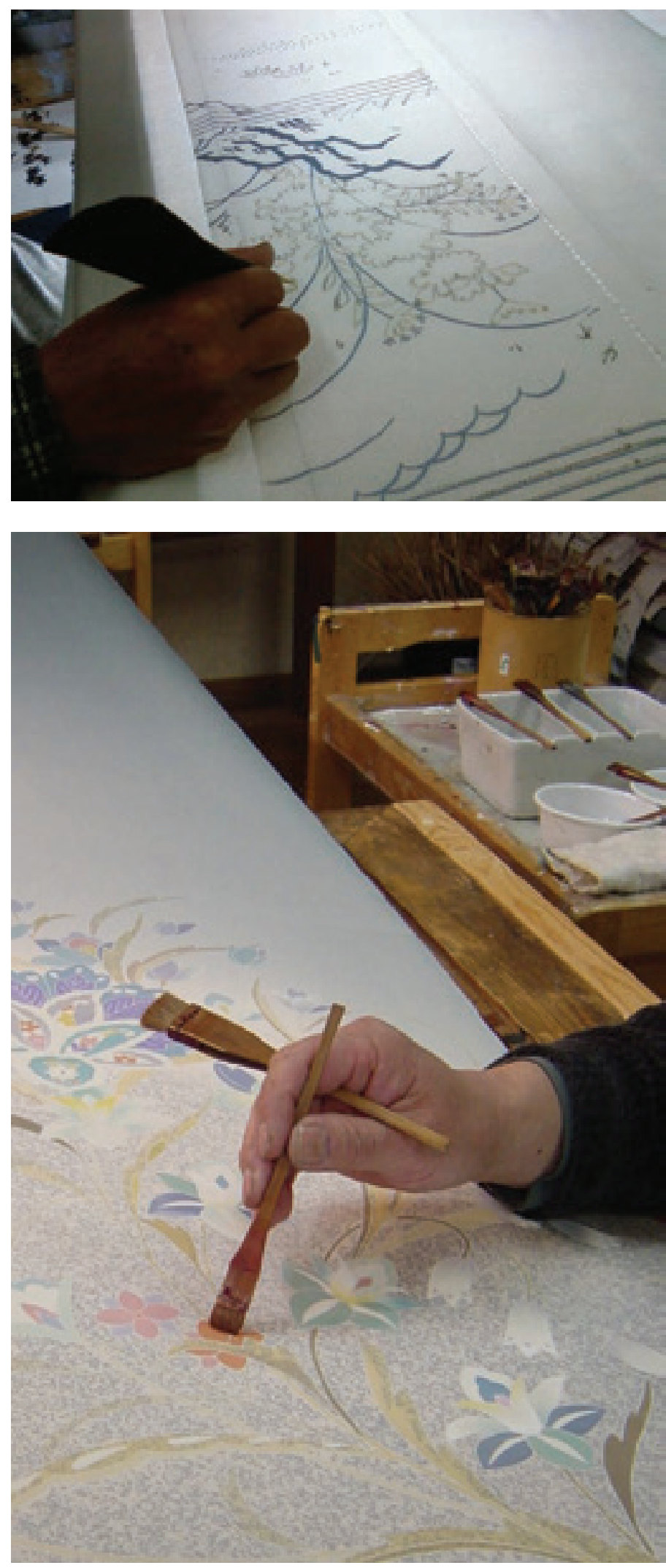

Figure 8.8 Tegaki yuzen: First, an outline of the base drawing is overdrawn with itome nori; then dye is applied within the outline.
The itome gata technique was developed in the late Edo period by pasting itome nori on to the fabric using stencils, ${ }^{8}$ as opposed to piping design outlines by hand. From very early times in the Ise district of Japan, stencils (katagami) were made from two or three pieces of Japanese paper glued together with persimmon tannin. Designs were created by cutting out the pattern, through which dye was applied on to the fabric. This method was frequently used for dyeing samurai clothes in the Edo period. The adoption of this technique resulted in itome gata, followed by yuzen (see Figure 8.9). Kata itome is a combination of techniques, in which two or more stencils are overlayed to produce more intricate designs. The kata itome yuzen process (a combination of stencil, starch paste and dyeing) evolved alongside production systems, as demand increased for the kosode. As a result, yuzen technology became a highly established and common practice.

In the Meiji period (1868-1912), a research and instruction organisation was established to protect and promote the value of craftwork production in Kyoto. The organisation sent artisans to study abroad and invited professionals from the West to introduce new techniques while also preserving traditions. In 1877 utsushi nori was invented - a process that uses dye, mordant and starch. Its importance was that it performed the function of both dyeing and resist-printing. Yuzen was put to practical use, with the application of utsushi nori and stencils. In 1890 Japan started to import chemical dyes and this, combined with these developed technologies, facilitated mass production. As a result, yuzen became affordable to the general public.

This methodology allows intricate and complex designs to be cut on several stencils, through which iro nori paste - a mixture of artificial dyes and sweet rice starch - is pushed, or brushed through onto the surface of the fabric (see Figure 8.10). The exact design appears when the stencils are removed. Next, steaming the fabric adds heat and moisture, and this enables the dyes of the iro nori to transfer on to the fabric. In cooperation with a business promotion policy by Kyoto Prefecture, this technique continued to develop 
and contributed to the establishment and reconstruction of Kyo-yuzen.

\section{New technology after kata yuzen}

From the Meiji to Showa period, many new techniques from the West were introduced. This included technology developed in England that allowed for six-colour printing (Adam Parkinson's 1785 improvement to Thomas Bell's roller printing device, which achieved printing of up to six colours on to calico) and also the silk-screen process. The silk-screen process did not require the same standard of skill as that of the yuzen artisan and designs could be as wide as the stencil itself, resulting in a greater area of printing in a single application. The process lent itself to the production of low-price products and products other than kimonos.

In roller-printing technology, the design is engraved on to a copper plate roll, and nassen nori (reactive dye) is applied along the engraved plate and then printed (see Figure 8.12). This system was perfect for printing fabric for kimonos that required repeat patterns.

The Showa period (1926-89) was one of rapid economic growth in Japan and Kyoyuzen production peaked in 1976 . However, a rapid decline followed, as the popularity of Western trends and fashions in clothing began to dominate Japanese culture. As a consequence, the number of Kyo-yuzen artisans declined. From 2000 inkjet print technology was exploited, taking advantage of its ability to dye without the requirement for physical patterns and also its Giclée (squirt or spray) technology of blowing fine particles of ink on to fabric (and other substrates). Since inkjet technology offers a more economical alternative to conventional yuzen, it is a production method that now dominates the contemporary kimono market.

However, until the advent of inkjet printing technology, the yuzen technique remained the most refined method of printing on fabric. For example, the colour depth attainable in the silk-screen process is inferior to yuzen, and the completed design often lacks the sharpness of the outlines yielded through yuzen techniques.
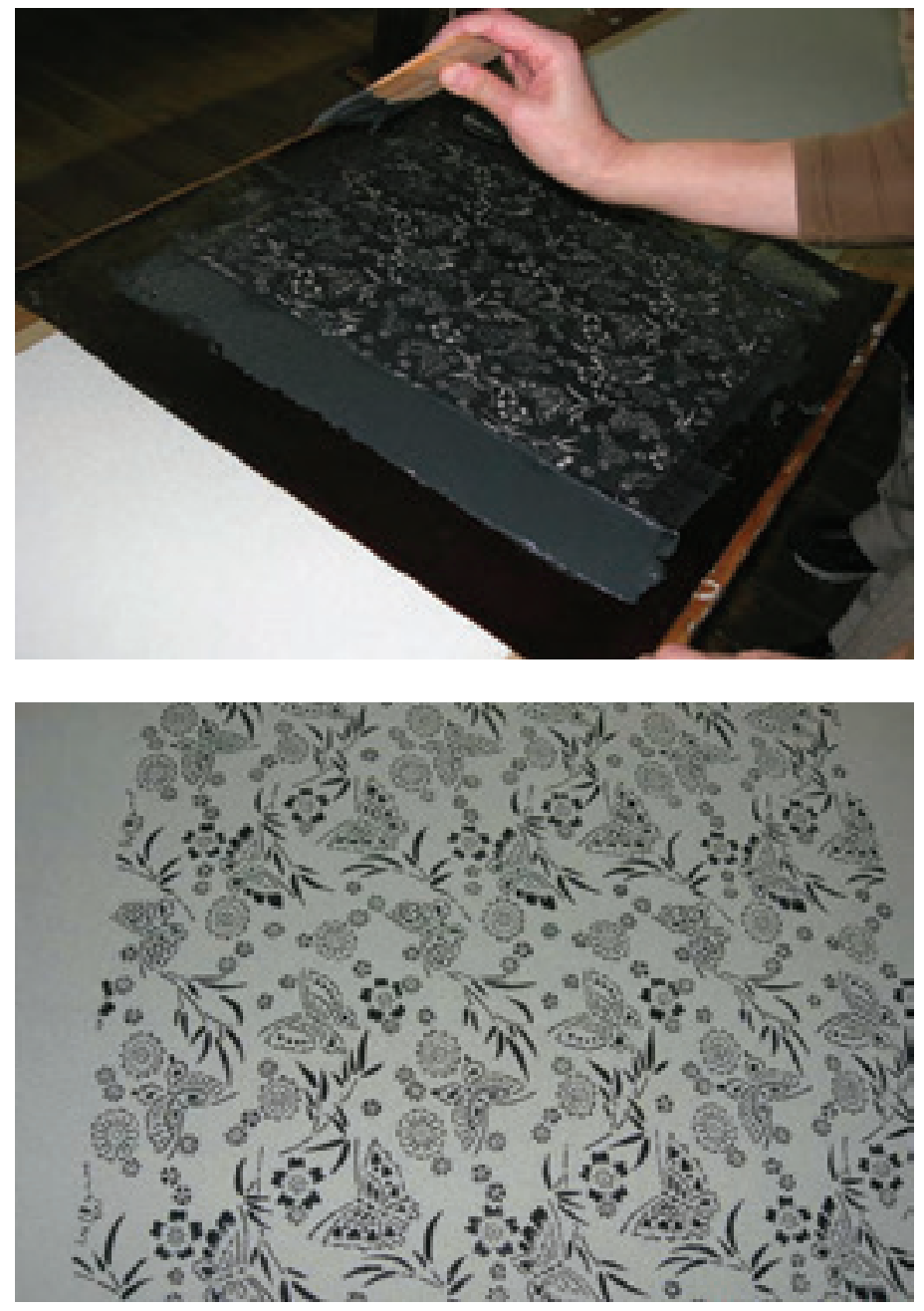

Figure 8.9 Itome gata yuzen: The outline of the base drawing is pasted on, using gum starch through a katagami stencil; it is the starch medium that is pasted on to the cloth.

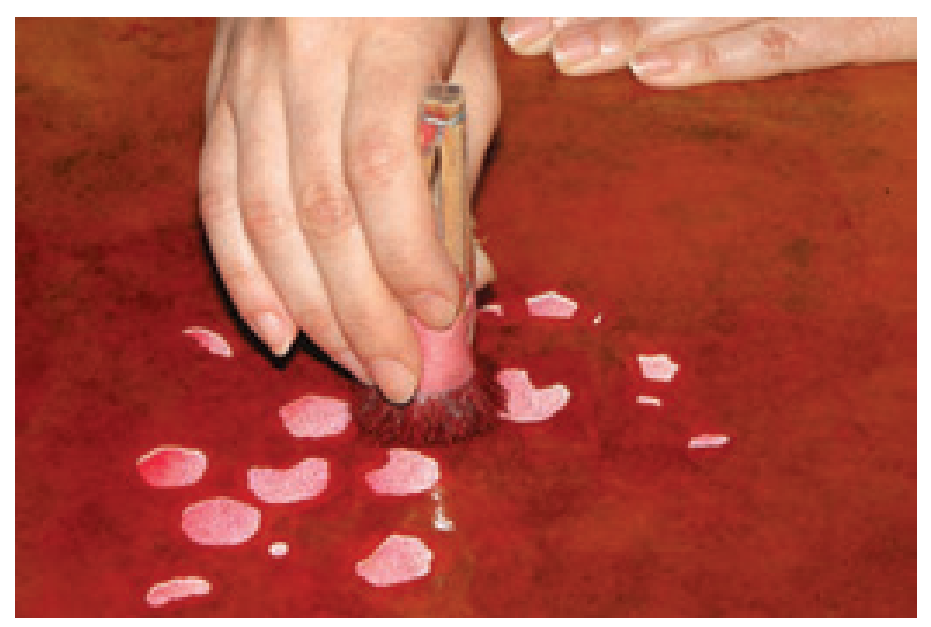

Figure 8.10 Kata yuzen: iro nori paste is brushed through the stencil on to the fabric 

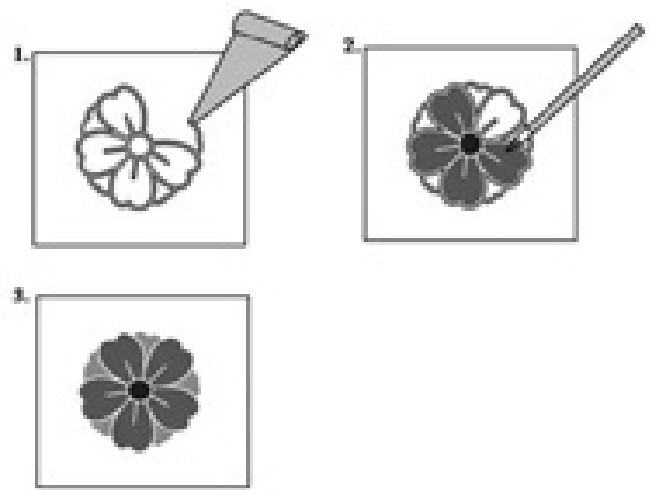

Tegaki yuzen: The outline of the base drawing is overdrawn with starch called itome nori - piped lines of starch. Dye is then applied within these lines.
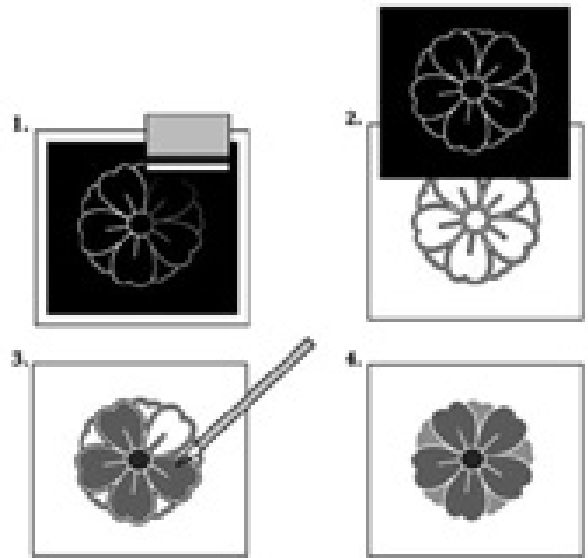

Itome gata yuzen: The outline of the base drawing is pasted with starch, using a stencil called itome gata. The stencil is then removed. A continuous pattern is produced by repeating the stencil process. The dye is applied within the designs, and different coloured dyes can be applied.
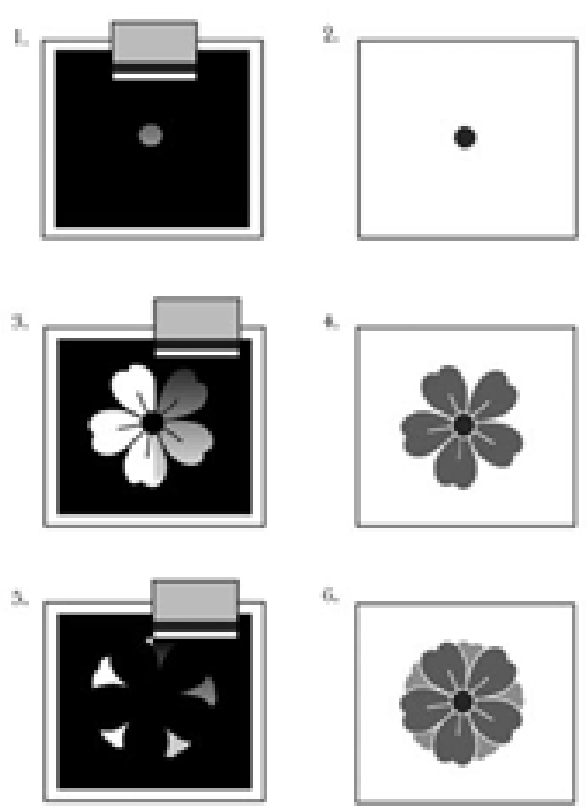

Kata yuzen: The outline of the base drawing is pasted with starch using a stencil called iro nori. The stencil is then removed. The same work is repeated by using other stencils and other colours.

Figure 8.11 The art of Yuzen - the different effects achieved through a variety of techniques and processes. 


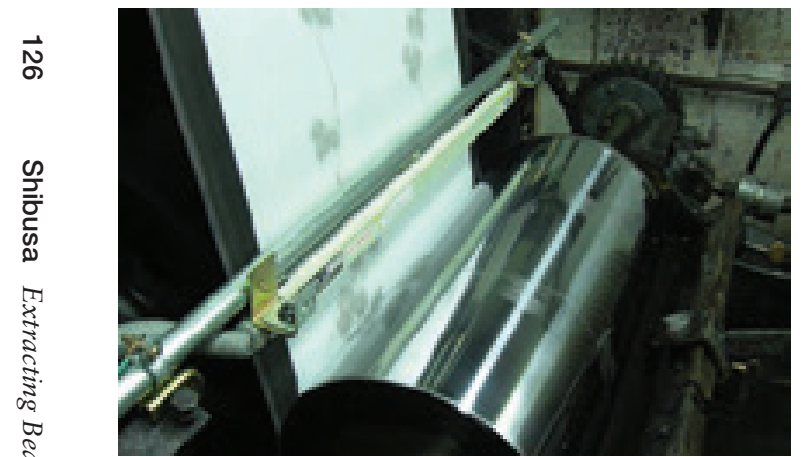

Figure 8.12 A roll-printing machine.

In addition, the roll-printing machine can print no more than 12 colours - it is, therefore, not possible to utilise large numbers of colours, or print connected designs, over seams. These new techniques cannot express the richness and complexity of designs to the same standard as yuzen; simply put, the yuzen technique produces a product of superior quality.

The use of inkjet printing in kimono production is the most radical change to occur in the field for centuries. Since 2000 it has become established as the alternative method of production to the yuzen technique (see Figure 8.13). Inkjet technology allows for an infinitely greater range of rich colour, expression and gesture than yuzen. It can dye more splendid and intricate designs, and can easily apply colour gradation effects. It has brought both efficacy and value to kimono production.

The rise of inkjet technology has also had a social impact on yuzen production. The process of tegaki yuzen (or yuzen) is based on a strict division of labour. The division of labour proceeded in tandem with industrial expansion, and contributed to a highly developed production technique. However, in the period of industrial decline, lower efficiency and high costs became factors, causing exhaustion. A boom in the price of kimonos started with rapid economic growth in the 1970s: prices for kimonos tripled from 1971 to 1981 . Its growth equated to nearly $¥ 2$ trillion, as production volume expanded and unit prices grew. But the revenue declined to $¥ 342$ billion in 2009 (see Figure 8.14).
The production of yuzen fabric for kimonos decreased from its peak of 16.52 million pieces in 1971 to 850,000 pieces in 2003 (see Figure 8.15 ), and dropped even more thereafter. Due to this decline, both manufacturers and distributers have closed, are closing, or are facing bankruptcy (see Figure 8.16).

Figure 8.14 The kimono market, 19712001 and 2004-9, showing the continued decline in the twenty-first century.

In addition, the number of kimono manufacturers declined sharply between 1987 and 2004. The ageing (and demise) of the last generation of artisans, combined with a decrease in new artisans entering the industry, has had a detrimental impact. The problem is not only that fewer people want to become artisans, but also the length of the training.

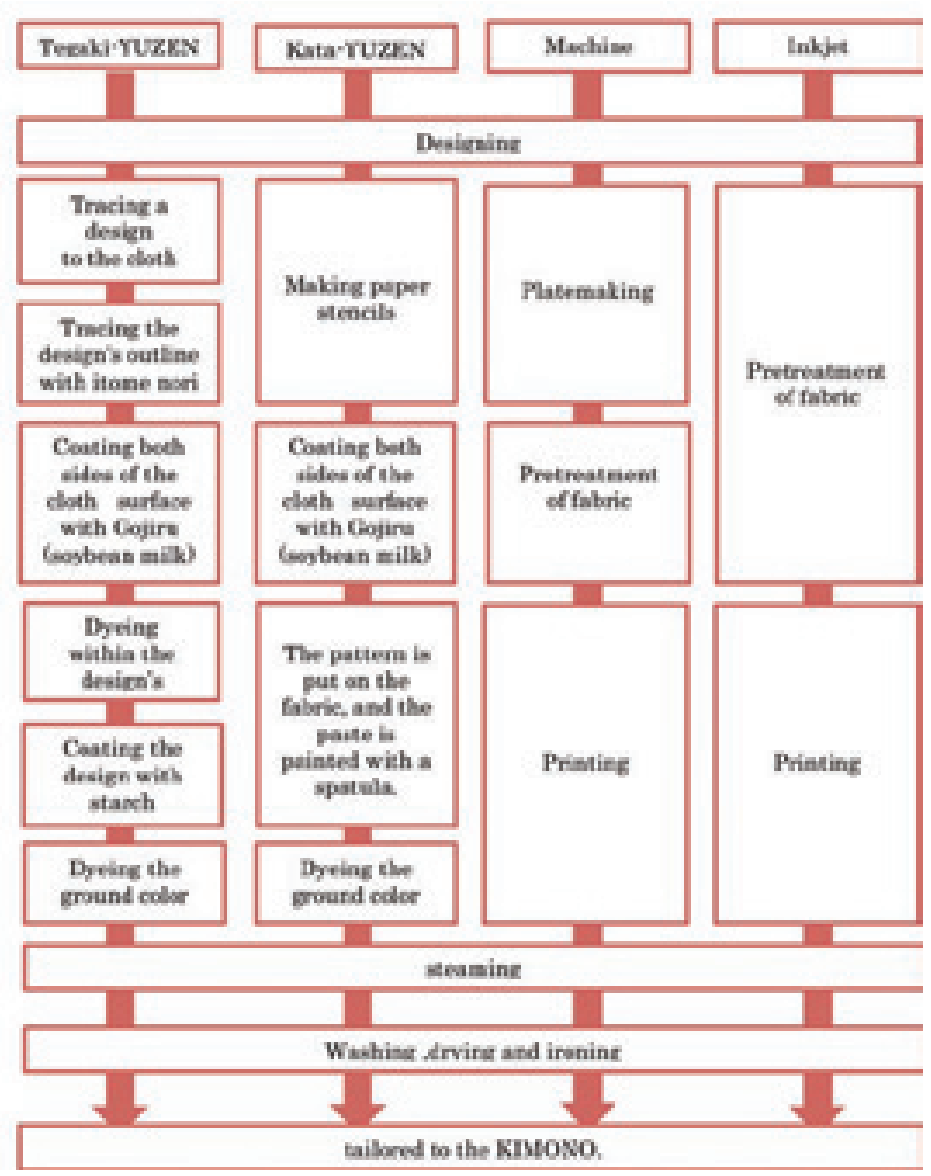

Figure 8.13 Production process according to production method. 

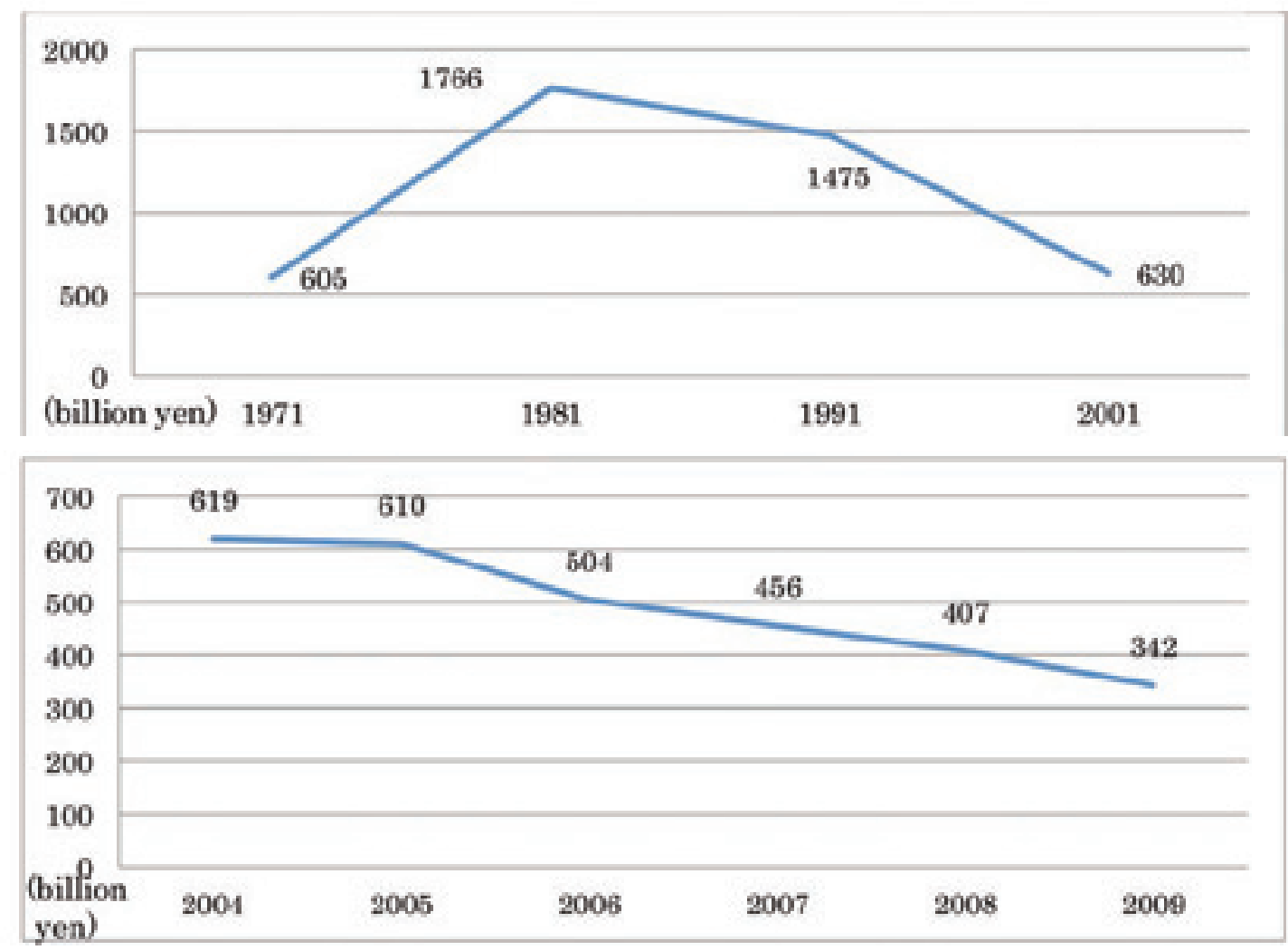

Figure 8.14 The kimono market, 1971-2001 and 2004-9, showing the continued decline in the twenty-first century. Yano Research Institute

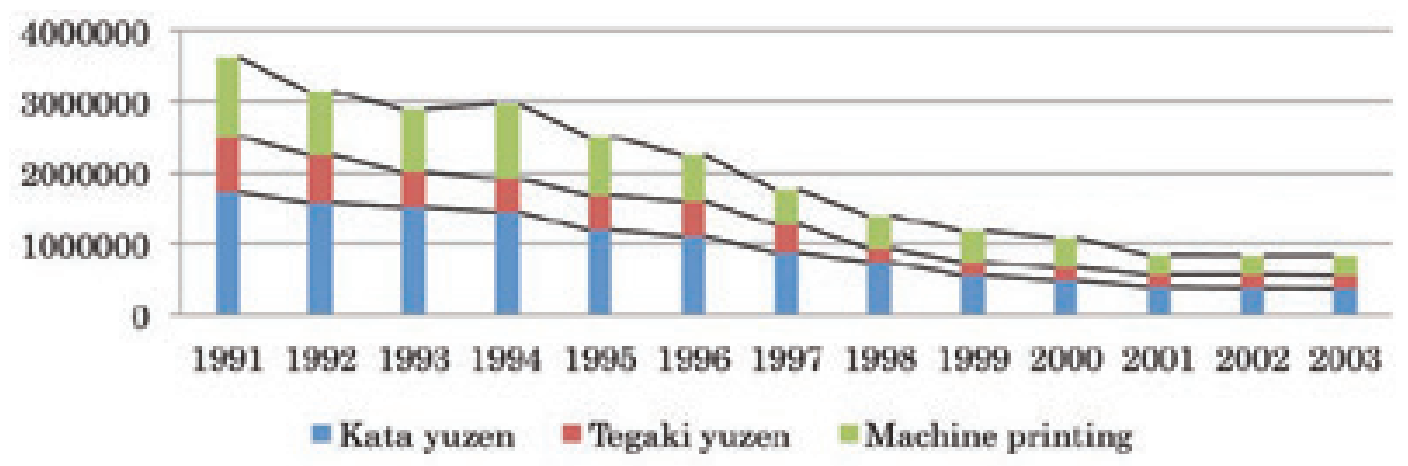

Figure 8.15 The production of yuzen for kimonos. Kyo-yuzen Kyoudou Kumiai

It takes 10 years of intense training to become a fully fledged artisan and during this period apprentices receive extremely low wages. Furthermore, once an apprentice has achieved the status of artisan, there is no guarantee of securing enough work, because of the current decline in demand for kimonos.

The distribution system for kimonos has also had a negative effect on artisans. As shown in Figure 8.17, this distribution system

\begin{tabular}{|l|l|l|}
\hline & $\begin{array}{l}\text { Manufacturing } \\
\text { enterprises }\end{array}$ & Employees \\
\hline 1987 & About 3320 & About 25100 \\
\hline 2001 & About 1042 & About 8000 \\
\hline 2004 & About 1300 & About 5600 \\
\hline
\end{tabular}

Figure 8.16 Yuzen manufacturing enterprises and employees, 1987-2004 (approximate numbers). Kyo-yuzen Kyoudou Kumiai 


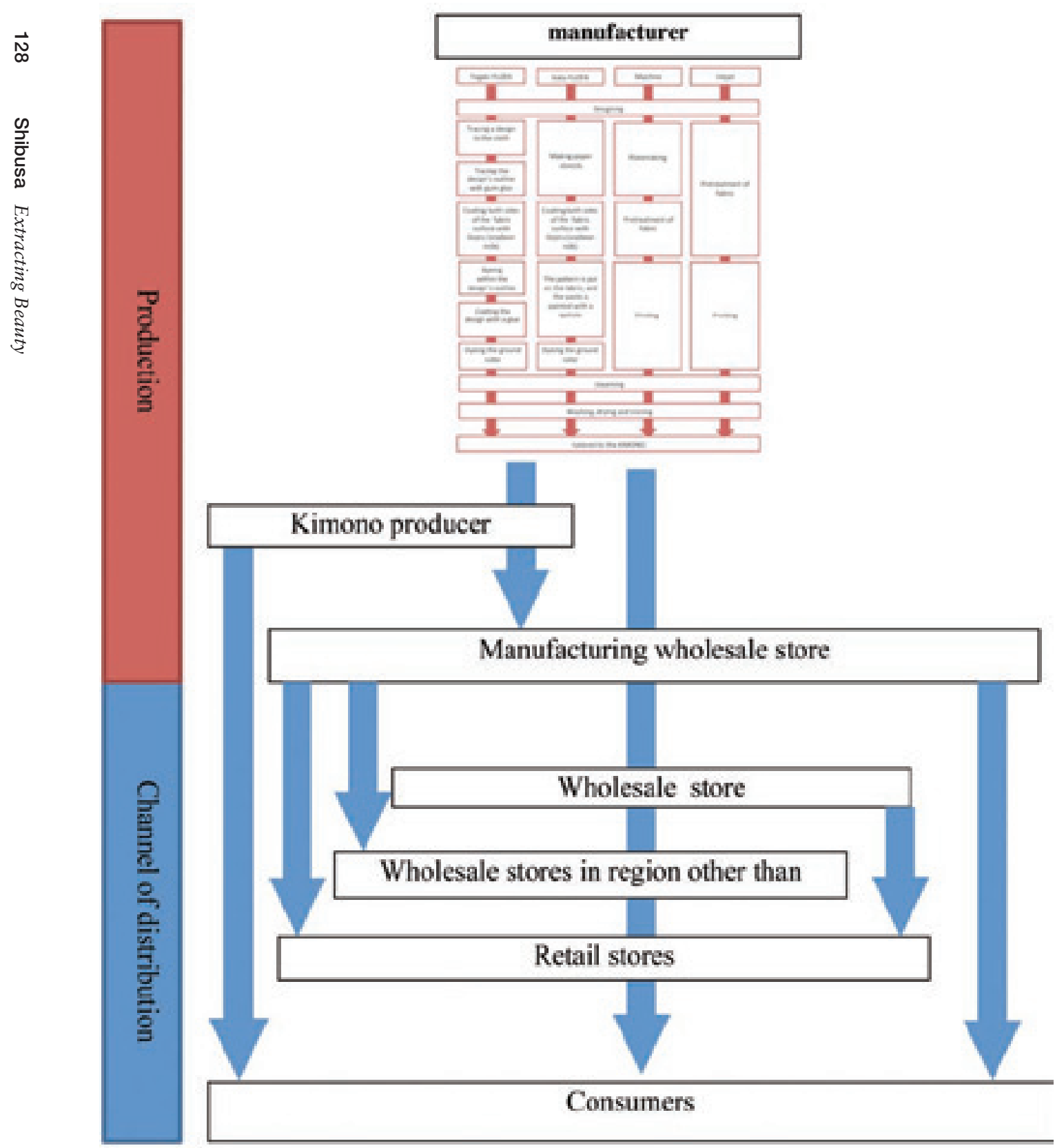

Figure 8.17 The distribution system for the kimono.

is very complicated and involves many commissioning agents. It consists of roughly three kinds of business categories: manufacture, wholesale and retail. With kimono demand falling, the kimono business has been trying to survive by cutting manufacturing costs. As a result, while artisans are expected to produce kimonos of ever higher quality, their wages have declined.
Management is finding that it is simply not financially viable to train new artisans. If there are no artisans, not only Kyo-yuzen but also the kimono culture itself is in danger of extinction. This is why inkjet technology has been widely accepted - as a means to facilitate cheaper production while retaining the culture of the kimono in Japan. 
It is true, however, that new problems are emerging as the inkjet becomes a more common tool. First, the inkjet technique is challenging the traditional yuzen artisans. Because inkjet technology is superior to yuzen in terms of cost and speed, traditional yuzen production is vulnerable to price competition, which has resulted in artisans continually striving to improve their cost efficiency. Of course, economic factors that force artisans to accept impossible demands also existed prior to the adoption of inkjet technology. That is why the unique skill and technique of the traditional artisans have long been acknowledged and valued in the marketplace, even though the market is becoming dominated by kimonos produced using inkjet technology.

The biggest problem is in kimono design, which has deteriorated significantly. Why has design quality deteriorated? Is it because computer-based design allows anyone to design, which has led to a flood of designs that ignore the established rules of kimono? Certainly, computers do enable anyone, with even the most basic of skills, to design, whether they have knowledge of the history of the kimono and its production or not. Conventionally, kimonos were manufactured through a division of labour. Each worker had, and maintained, a high level of individual expertise. In contrast, inkjet printing can combine several processes of yuzen. Unfortunately many inkjet designers possess little knowledge about kimonos and this lack of knowledge is often apparent in the design - and can generally be discerned by consumers.

In the future, inkjet will play a significant role in yuzen and the tradition of Japan's kimono culture. Therefore, the fundamental question is: how does the current generation combine the inherited traditional techniques with contemporary technology without ending up with superficial designs?

\section{My own practice}

In my practice I remain acutely aware of my heritage of kimono culture: its techniques and production methods. I believe that I am pursuing a strategy that will facilitate the handing on of both traditional culture and contemporary techniques. What follows is an outline of the methodology I use for inkjet printing in my kimono design practice.

The production environment consists of:

$$
\begin{aligned}
& \text { operating systems: Microsoft } \\
& \text { Windows and Apple Macintosh; } \\
& \text { software: Adobe Photoshop; } \\
& \text { printers: Mimaki TX200 and } \\
& \text { Epson PM-10000. }
\end{aligned}
$$

The production steps are outlined in Figures 8.18, 8.19 and 8.20.

In the production process I pay great attention to incorporating key elements of traditional design while taking into account the characteristics of inkjet. Since inkjet printing sprays evenly on to fabric, it can tend to be impersonal and plain, which can produce a bland kimono. Conversely, tegaki yuzen (or yuzen) have high degrees of ink penetration. The control of a brush, by hand, can create even minute gradation. To recreate this quality of gradation through inkjet printing, it is necessary to include it in the design intentionally. For example, a pool of dyes on the edge of a design generates unique colour bleeding. Reproducing such bleeding makes it possible, therefore, to recreate these traditional effects in inkjet printing.

In addition, I emphasise traditional techniques, such as the use of traditional yuzen patterns (see Figure 8.21). Yuzen patterns contain a balance in their composition that flatters the female kimono wearer. This is the reason why yuzen patterns were inherited from the Edo period through to present times. Ignoring the inherited rules of kimono design will produce designs that lack traditional sensitivity. Of course, traditional and modern sensitivities are mutually exclusive in some aspects, which is why maintaining a balance between traditional and modern sensitivities is crucial. Not until the modern sensitivity has acknowledged the traditional can this accumulated knowledge of kimono design be passed on to the next generation.

However, it is difficult to know whether the balance between the old and the new is 

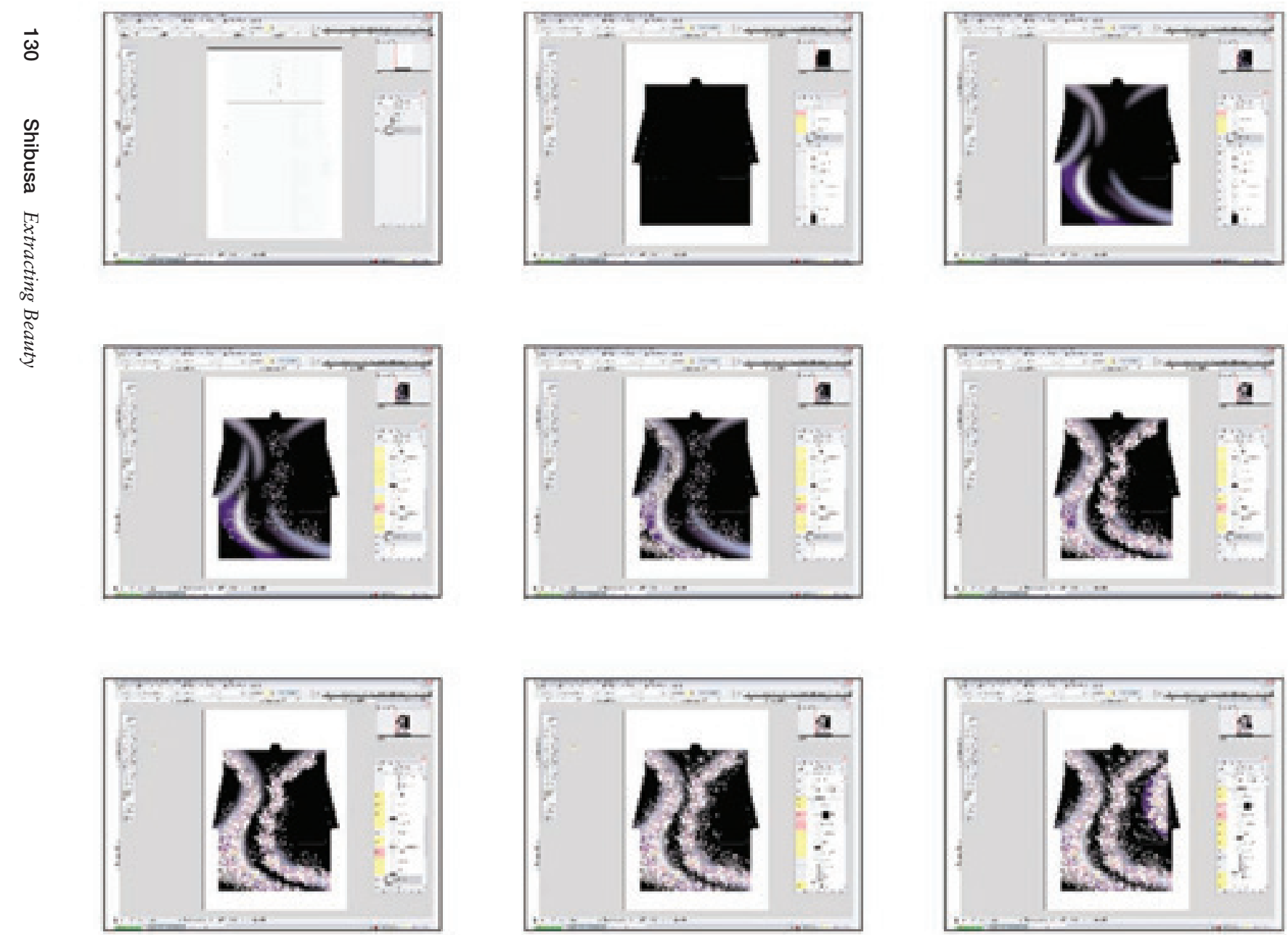

Fig 8.18 The design is created, using Adobe Photoshop.

The size of the data when designing is equal to the actual size of the kimono, which is $164 \times 189 \mathrm{~cm}$.
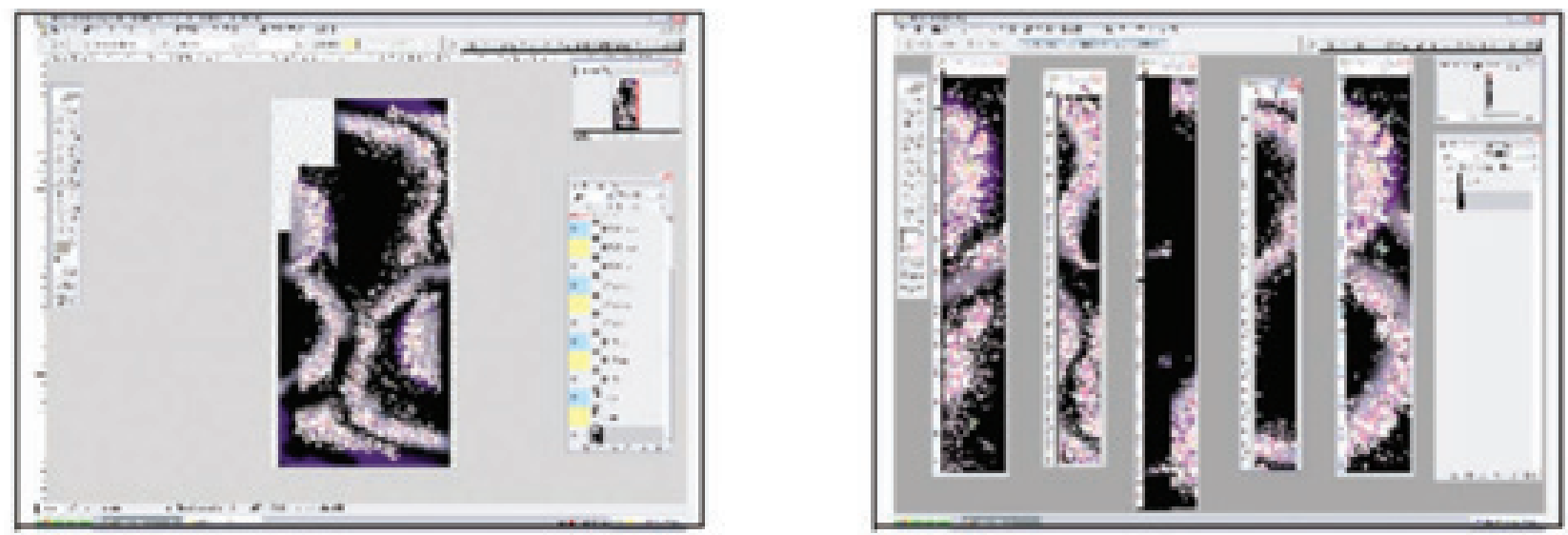

Figure 8.19 The complete design is converted into data that is suitable for printing. The data is divided into five sets of printing data. 

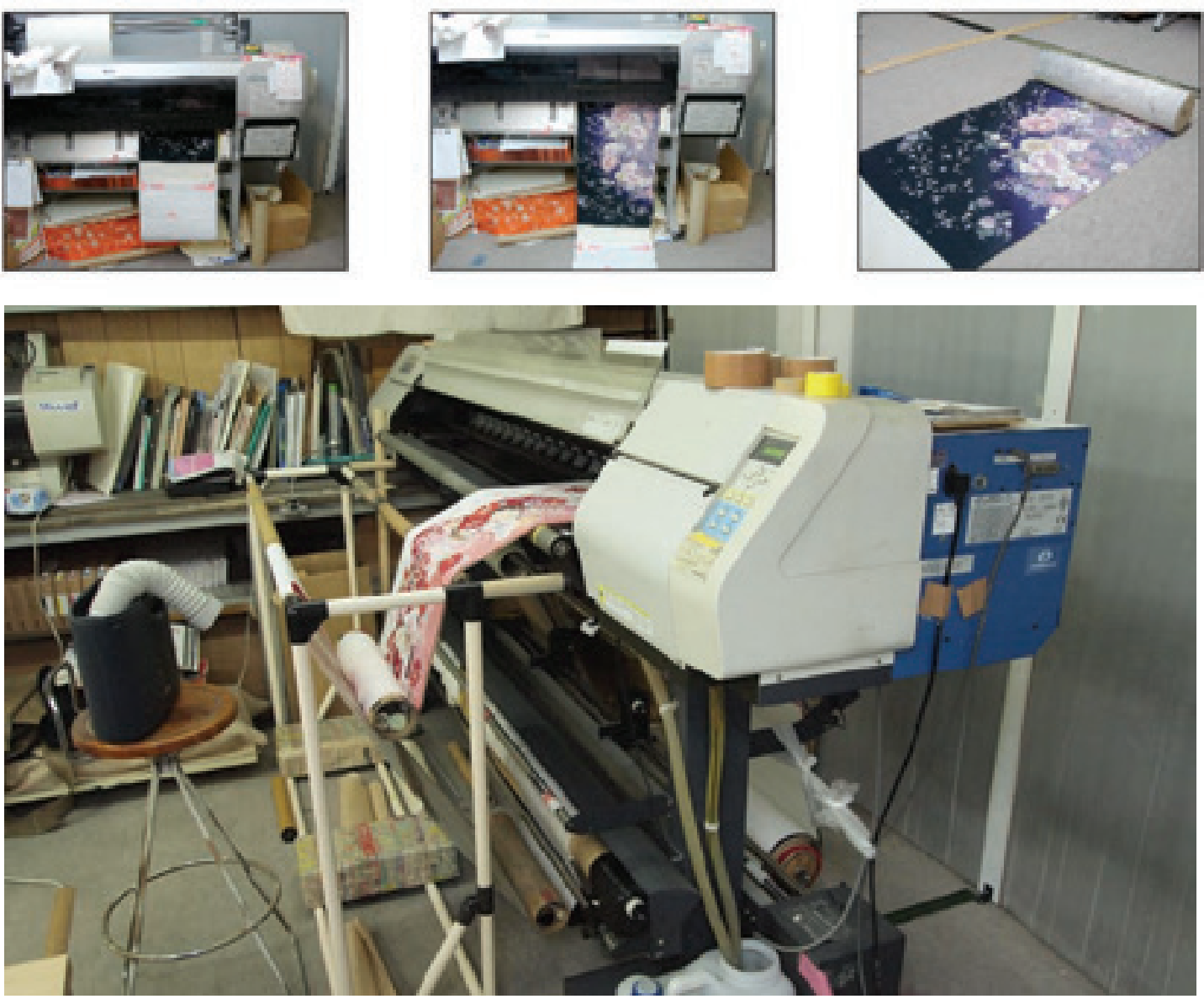

$\vec{\omega}$

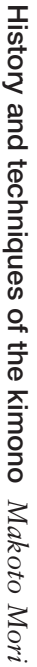

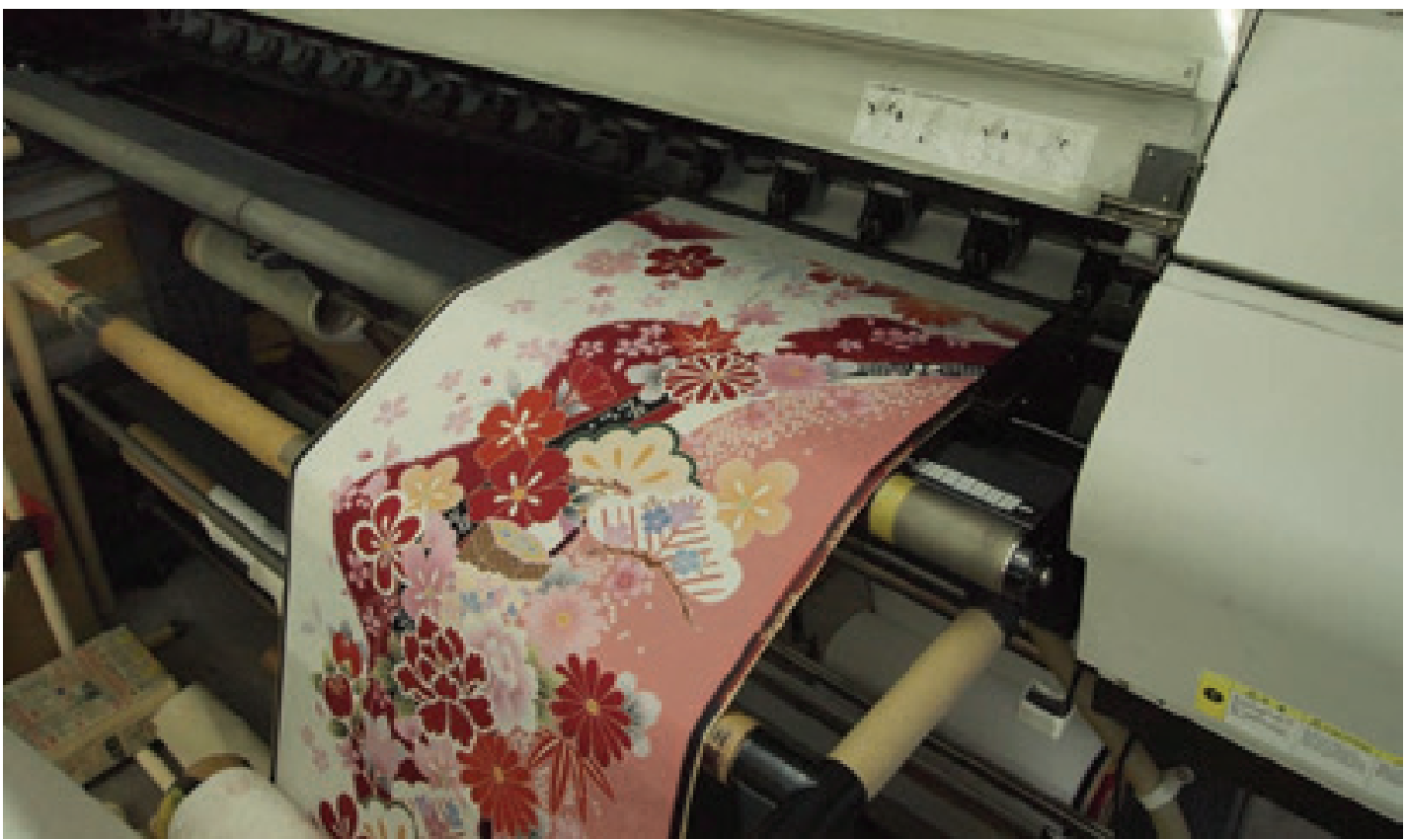

Figure 8.20 The five sets of printing data are printed on to a piece of cloth. The cloth of the kimono is generally silk (but can be other materials). The length of a piece of cloth is between 13 and 17 metres, according to the type of kimono. Originally inkjet printers used acidic dyes, but today reactive dyes are most commonly used (the Mimaki TX200 printer uses reactive dye, while the Epson PM-10000 uses acidic dye). 


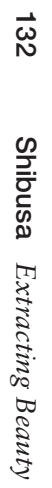
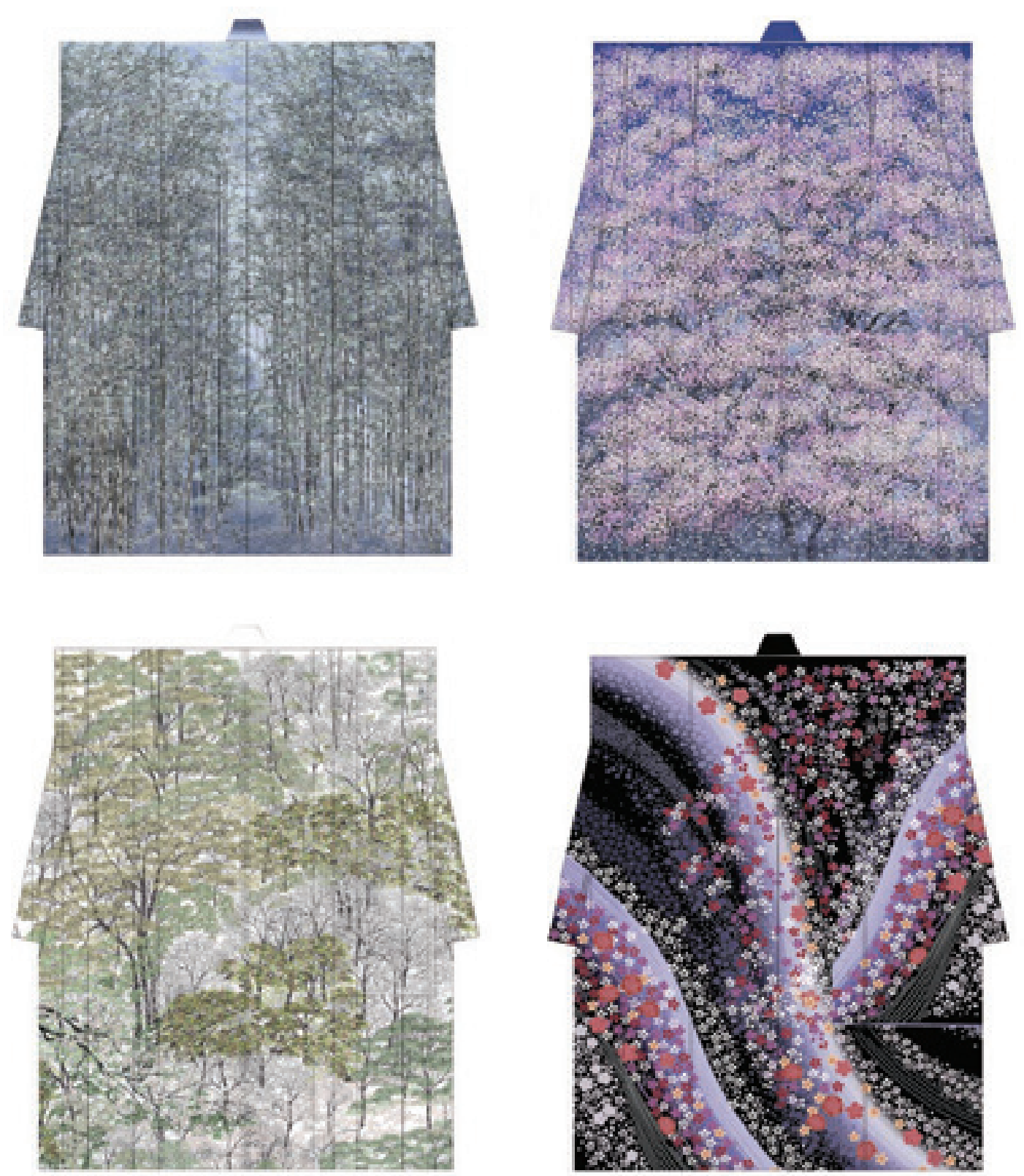

Figure 8.21 Kimono designs by Makoto Mori, using computer graphics. (C) Makoto Mori 
popular in today's market, since kimono manufacturers do not have much contact with consumers. To address this lack of data, I have been working on a project to find the critical point of balance between traditional and modern sensitivities. Essentially it is a method of ascertaining and recording public reception and responses to designs by producing doll costumes (see Figure 8.22). As the design is held on computer it is flexible - it can be enlarged, or reduced in size, to suit. Thus a kimono design can be used for either a doll or enlarged to fit a human being.

To manufacture a kimono design for a doll that appeals to ardent fans and then sell it online via internet auctions also allows me to gather and evaluate the potential quality of the design, by studying site visitor numbers and responses. My research indicates that 80 per cent of doll purchasers and collectors are women. This market sector is, therefore, an ideal platform for promoting my designs, since it is mainly women who wear kimonos today.

I came to realise through this strategy that it is crucial to narrow the distance between manufacturers and consumers. Because the kimono, in a contemporary context, is considered more as an art object, the range of people that appreciate its value is small.
In essence, only this small, discerning group understands and values the specific techniques of traditional and contemporary artisanship.

Unless we change our attitude to embrace new methods of creation and design, we may allow the tradition of the kimono to fade away altogether, along with many other traditional techniques. Ultimately, our knowledge of this industry might not survive. Therefore, it is time for both artisans and designers to think how they can use and celebrate traditional kimono culture, techniques and knowledge.

\section{The future of the kimono}

Today the kimono market continues to shrink. Although it may be possible for traditional kimonos to survive as artistic and luxury items, for regular use (and wear) it is inkjet printing that may be able develop a traditional kimono culture in a contemporary atmosphere. For example, the potential value of such techniques is not limited to kimono fabric alone. To apply traditional yuzen techniques and know-how in new areas, such as interior decoration, will protect the heritage of traditional techniques.

It is important to appreciate that even though products that apply traditional
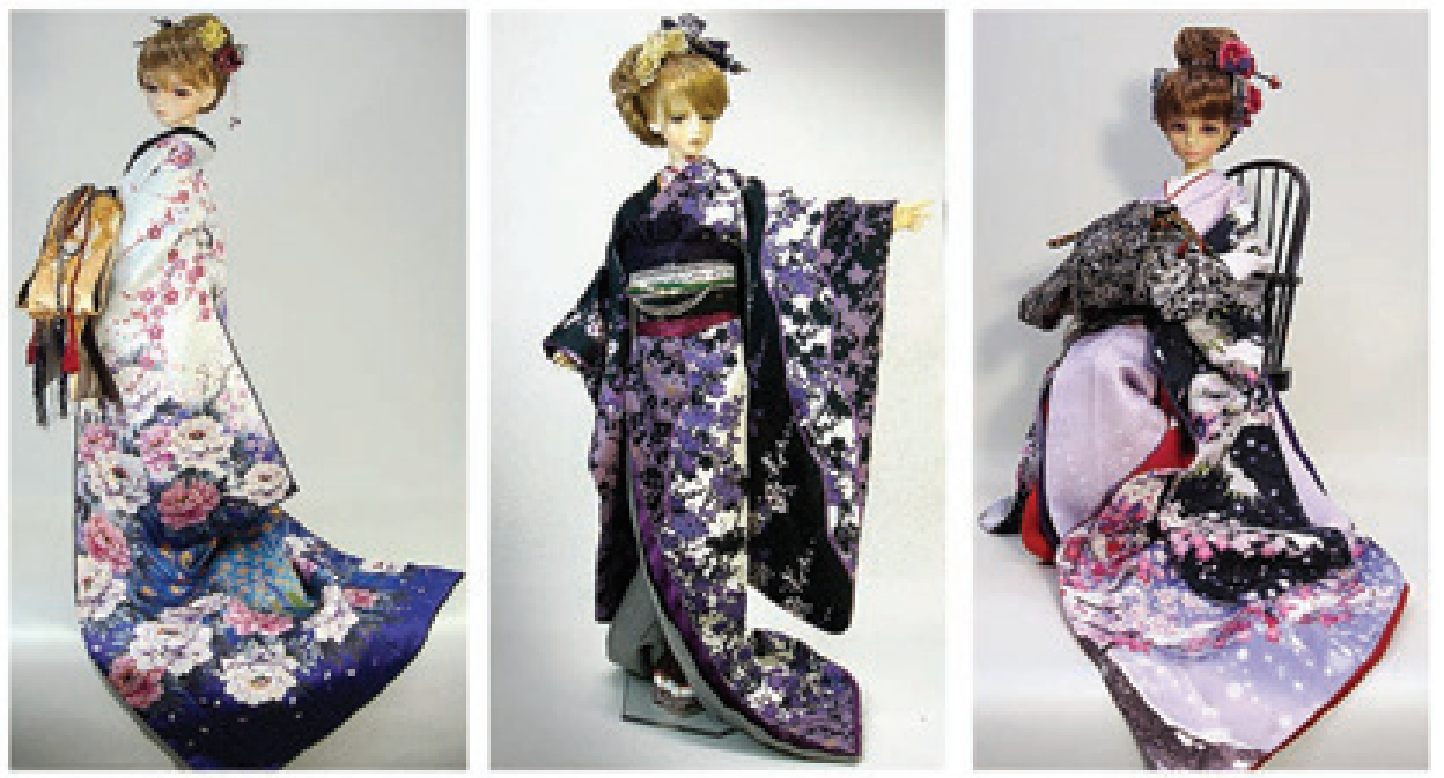

Figure 8.22 Doll-size kimono designs are an innovative method of researching the market. (c) Makoto Mori 
techniques - such as kimonos printed by inkjet - are excellent, such traditions could still become obsolete if they are not valued. Only when it is relevant and alive in the present can tradition exist as it is. For the next generation to inherit culture and tradition, should we not also seek to meet the needs and desires of the contemporary consumer? Being willing to learn from consumers is what is needed, so that traditional culture and techniques can be absorbed into people's everyday lifestyle. In this way, both traditional and new techniques can evolve, be refined and redefined succeeding in a contemporary context by mirroring modern life.

\section{Notes}

1 S. Takata, Fukushoku no rekishi (History of clothes) (Tokyo: Chuoukouron-sya, 1995), 149.

2 S. Kawakami, Kuge no Fukushoku (Court noble's clothes) (Tokyo: Shiko-sha, 1994), 45.

3 Takata, Fukushoku no rekishi, 148.

4 J. Tcuzu, Daikoukai-zidai sousho (Age of discovery's library), (Tokyo: Iwanami Shoten, 1970).

5 The design of the yuzen is called yuzen pattern today. The process was used to dye motifs such as flowers, animals and scenery with various colours.

Yoshio Igidani (2001) Kyo-yuzen Surizome rekishi to giho (Kyo-yuzen suri-zome, history and technique'), (Kyoto: Kyoto yuzen kyodo kumiai, 2001).

7 Itome means 'thin line-like string'. The principal ingredient of a traditional itome nori is a glutinous rice powder, although today gum starch is a main ingredient.

Gata and kata mean 'stencil'.

\section{Further reading}

Doshisha University, Study of Humanities and Social Sciences, Wasou orimono-gyo no kenkyu (Research of kimono industry) (Kyoto: Minervashobo, 1982).

Itakura, T., Genshoku senshoku daijiten (Dictionary of dyeing and weaving) (Kyoto: Tankosha, 1977).

Kyoto City Senshoku Shikenjyo, Tegaki Yuzen-zome no gijyutsu to gihou (Technique of Tegaki-yuzen) (Kyoto: Senshoku-to Seikatsusha, 1997).

Kyoto Prefectural Technology Center for Small and Medium Enterprises, Kyoto-Fu Sangyo no tenbo 2005 (View of industry of Kyoto 2005) (Kyoto: Prefectural Technology Center for Small and Medium Enterprises, 2005).

Nagasaki, I., 'Kosode kara Kimono he' (From kosode to kimono), Nibon no Bijyutsu 435 (2002).

National Museums of Japan, www.emuseum.jp Tanida, E., Nihon Fukushoku-shi (History of Japanese clothes) (Tokyo: Koseikan, 1989).

Yano Research Institute, Kimono Sangyo Hakussho 2010 (Kimono industrial white paper 2010) (Tokyo: Yano Research Institute, 2010).

Information on Makoto Mori's designs is available at: www.tocomarimo.com www.ian-kimono.com/ and http://fotologue.jp/iankimono 